\title{
Assessing the Accuracy and Feasibility of Using Close-Range Photogrammetry to Measure Channelized Erosion with a Consumer-Grade Camera
}

\author{
Fangzhou Zheng ${ }^{1,2,3}$, Rene Wackrow ${ }^{4}$, Fan-Rui Meng ${ }^{2}$, David Lobb ${ }^{3}$ and Sheng $\mathrm{Li}^{1,2,3, *}$ \\ 1 Fredericton Research and Development Centre, Agriculture and Agri-Food Canada, Fredericton, \\ NB E3B 4Z7, Canada; Fangzhou.Zheng@canada.ca \\ 2 Faculty of Forestry \& Environmental Management, University of New Brunswick, Fredericton, NB E3B 5A3, \\ Canada; Fanrui.Meng@unb.ca \\ 3 Department of Soil Science, University of Manitoba, Winnipeg, MB R3T 2N2, Canada; \\ David.Lobb@umanitoba.ca \\ 4 Institute for Spatial Information and Surveying Technology, Mainz University of Applied Sciences, \\ 55128 Mainz, Germany; rene.wackrow@hs-mainz.de \\ * Correspondence: sheng.li@canada.ca; Tel.: +1-506-460-4467
}

Received: 2 April 2020; Accepted: 25 May 2020; Published: 27 May 2020

\begin{abstract}
Water-induced channel is one of the main forms of soil erosion in cultivated fields. Channelized erosion is often measured by the volume of the channels. Traditionally, the measurements were conducted with rulers or measuring tapes. However, these traditional methods are generally time- and labor-consuming and can cause soil surface disturbance. Close-range photogrammetry with a Consumer-Grade Camera (CGC-CRP) provides an alternative way of measuring channel volume and can overcome limitations of traditional methods and provides much higher spatial resolution. However, quantitative information on the accuracy of this technique is rare. In this study, the accuracy of the CGC-CRP method under different settings were examined with an in-house experiment and validated with a field experiment. In the in-house experiment, a wood board surface with Artificial Channels (AC) of different shapes, orientations, and sizes were built. These ACs were surveyed using the CGC-CRP method with a series of settings of shooting angles and image overlapping rates. Selected cross-sectional areas were extracted to compare against manual measurements to assess the absolute and relative errors of the CGC-CRP method. The applicability of the CGC-CRP method with different settings was evaluated by comparing time consumption and the size of detection areas. The results indicated that in order to maintain an acceptable accuracy level, the image overlapping rate should be $\geq 70 \%$, and the shooting angle should be in the range of $60^{\circ}$ to $80^{\circ}$. For the channel shape, the accuracy for V-channel was $\sim 15 \%$ higher than that for U-channel. For the U-channel, the impact of the channel orientation on the accuracy was not significant when the shooting angle was relatively high, whereas for the V-channel, the vertically oriented channel had higher accuracy than horizontal or angle channels. Last, channel size did not strongly affect accuracy when the channel was vertically orientated, and the shooting angle and image overlapping rate were set in the optimum ranges. However, when the shooting angle or image overlapping rate was low, or when the channel was angled or horizontally orientated, the accuracy was lower with larger channel size. In the field experiment, under the optimum camera setting, the error for the ten cross-sectional areas was about $1.6 \%$. This result suggests that the CGC-CRP method is promising in volumetric assessment of rill and gully erosion. The quantitative information on the accuracy provided in this study can help researchers to select the setting of CGC-CRP methods to achieve their required accuracy level.
\end{abstract}

Keywords: consumer-grade camera; close-range photogrammetry; rill erosion; gully erosion; Digital Elevation Model (DEM) 


\section{Introduction}

Water erosion is one of the main forms of soil erosion in cultivated fields, causing soil loss and crop yield reduction on site and environmental concerns off-site [1-4]. Water erosion is often shown as morphological changes or resultant morphological features. At the beginning of a water erosion event, erosion can be caused by raindrop splashing and surface runoff (in the form of sheet flow). It results in relatively uniform soil loss across the slope, which is termed sheet erosion. As the runoff depth increases, it starts to concentrate and incise into soil surface to form channels. Channels firstly appear as randomly located parallel small rills. As a rill develops, runoff cuts deeper into the rill bottom and widens the channel. Big channels that can be filled by regular tillage operation are called ephemeral gullies. The locations of these channels are often defined by topography so that they usually reappear at roughly the same locations each time even they are filled by tillage every year. When channels become too big to be erased by normal tillage operations, they are termed classic gullies [5-7].

Many methods have been developed to assess channelized water erosion by measuring the geometry and volume of channels. Traditionally, accurate assessment of channelized erosion is based on the measurement of multiple cross sections along the channel using a ruler and a measuring tape or a micro-topographic profiler [8,9]. These two methods are simple, low-cost, and widely used [10]. For the first method, a measuring tape is used to measure the horizontal distance across the channel; at discrete locations, a ruler is used to measure depths, based on which the cross section of the channel can be established. For the second method, an ordinary micro-topographic profiler is used. It usually consists of an array of dropping pins arranged along a wooden frame at $2 \mathrm{~mm}$ to $5 \mathrm{~mm}$ intervals. The wooden frame is placed at the ground level along the cross-sectional transect, and the dropping pins are lowered to the channel bottom, and the profile is recorded using a camera [11]. The traditional method can achieve high accuracy in some cases. For example, a field assessment of erosion damage by Herweg [12] indicated that a carefully implemented survey with a ruler and a measuring tape usually has errors less than $15 \%$. However, the volume calculation is based on measures of discrete cross sections. Errors can be high when cross section changes erratically along the channel, which is very common due to the erratic nature of surface runoff. Moreover, these methods are generally time- and labor-consuming and, therefore, not practical for surveying large areas. As direct contact is required, they may also cause disturbance to the soil surface.

Many studies have used Light Detection and Ranging (Lidar) technology, such as aerial Lidar and terrestrial Lidar, for topography measurement [13-18]. Lidar data can be used to generate a Digital Elevation Model (DEM) for the soil surface. Channel volume can be calculated from the DEM so that it overcomes the limitations of discrete cross section measurements. For the aerial Lidar, the DEMs produced usually have a horizontal resolution greater $0.5 \mathrm{~m}[19,20]$ and an accuracy of about $0.3 \mathrm{~m}$ or better [21]. This is sufficient for detecting general surface form or classic gullies, but not for measuring small erosion channels (i.e., rills), which are usually smaller than $0.3 \mathrm{~m}$ wide and $0.3 \mathrm{~m}$ deep. The aerial Lidar is also limited by weather conditions and vegetation cover. Besides, aerial Lidar scan is costly. For the terrestrial Lidar, the resolution and accuracy are much higher than aerial Lidar. However, the equipment is very expensive and heavy to carry in the field. Moreover, the set-up of terrestrial Lidar is time-consuming as it requires careful calibration and leveling. Photogrammetry has also been used in water erosion studies, especially for the channelized erosion. Photogrammetry is the technique to extract 3D information of objects through photographs [22]. Compared to the traditional method, photogrammetry has the advantage of minimal soil disturbance and low labor and time requirement. Recently, photogrammetry became more popular with the Structure from Motion (SfM) technique [23]. $\mathrm{SfM}$ is a technique used to reconstruct three-dimensional structures from two-dimensional image sequences that can be coupled with motion signals. With the SfM, photogrammetry becomes more reliable due to the robustness and efficiency of the algorithm proposed by Lowe [24]. Photogrammetry is classified based on camera location during photography into aerial photogrammetry and close-range photogrammetry. For the aerial photogrammetry, the camera is usually mounted under an aircraft (e.g., Unmanned Aerial Vehicles (UAVs)), whereas, for the close-range photogrammetry, the camera is 
usually mounted on a tripod or handheld by a photographer. The aerial photogrammetry has long been used to monitor or measure soil erosion, especially ephemeral gully erosion [25-29]. With the advances in technology, numerous studies have applied aerial photogrammetry for assessing channelized erosion at different scales [30-39]. Recently, close-range photogrammetry has also been utilized to monitor processes of soil erosion in many studies [40-49]. Many researchers used Consumer-Grade Cameras (CGC) in their studies. To achieve a high level of accuracy, several researchers utilized different types of support tools or metal frames to maintain the stability of the camera for obtaining quality images $[43,47]$. Those frames added extra weight and were not convenient to carry in the field. Castillo [41] et al. reported a study that required more than one operator for taking the photogrammetric measurements. One operator was responsible for taking the photo, whereas the other operators set up the georeferences. These methods were inconvenient in practice. Therefore, Kaiser et al. [45] pointed out that, from a practical perspective, image capturing with a handheld camera should be the easiest and lightest way to reconstruct gully morphology. However, there is still large uncertainty associated with this method.

Several factors can affect the accuracy of close-range photogrammetric measurement. In general, measurement errors associated with photogrammetry can come from two sources: camera network geometry and channel geometry. The camera network geometry in photogrammetry was associated with the procedure of the photo-taking, including settings such as shooting angle (angle between the camera lens direction and the horizontal surface), image overlapping rate, number of images used, and so on. A study from Dai et al. [50] examined the error sources for photogrammetry in construction engineering applications and summarized that (1) for the shooting angle, the closer to $90^{\circ}$ (vertical image), the better quality of the images, thereby the better accuracy, and (2) for the image overlapping rate, the higher rate, the better accuracy. These trends were also reported by Golparvar-Fard et al. [51], who conducted a quantitative comparison regarding cost, accuracy, and ease of use of close-range photogrammetry. With respect to the channel geometry, only a few studies have been conducted. Giménez et al. [33] studied the accuracy of photogrammetric measurements of gullies (gully width ranges from $0.14 \mathrm{~m}$ to $17.6 \mathrm{~m}$; gully depth ranges from $0.2 \mathrm{~m}$ to $2.7 \mathrm{~m}$ ) and showed that the photogrammetric measurement was strongly influenced by the gully morphology, such as gully shape (e.g., U-channel versus V-channel). A major cause of the error is the shadow effect. Under natural conditions, the shadow effect occurs when there is shadow from sunlight or when part of the target surface is blocked. The shadow effects are usually associated with narrow and deep gullies. In Marzolff and Poesen's study, the factors affecting the accuracy of gully detection using photogrammetry were similar, including shadow effect; edge effect, resulting from the steep gully wall; and vegetation cover [35]. These previous studies revealed the major factors affecting the accuracy of close-range photogrammetry. However, they are mostly qualitative studies and each focused on one specific aspect of photogrammetry or a sub-group of factors. A systematic assessment on the accuracy of close-range photogrammetry in measuring the volume of water-induced channels is needed.

Overall, there is still a lack of quantitative information on how to use the close-range photogrammetry with a consumer-grade camera (CGC-CRP) to make accurate measurements of water-induced channels. Meanwhile, there is a lack of assessment on time and labor consumption associated with efforts to enhance accuracy with the CGC-CRP method. This information can be used to provide practical guidance for using the CGC-CRP method to measure the volume of water-induced channels and the size of any geomorphological features at large. Therefore, in this paper, the CGC-CRP method was tested on two types of surfaces, and the objectives are listed below.

1. To estimate the accuracies of the CGC-CRP method under different settings on detecting erosion channels and similar morphological features.

2. To assess the applicability of the CGC-CRP method under scenarios with various spatial, temporal, and resource constraints. 


\section{Materials and Methods}

\subsection{Study Surfaces}

Two surface types were tested: artificial surface and soil surface. The artificial surface was used to exam accuracies of different settings, whereas the soil surface was used to validate the recommended settings, which has a good performance on detecting artificial surface.

The experiment was carried out in the Fredericton Research and Development Centre, New Brunswick, Canada. The artificial surface (Figure 1) was established in a storage building of the center. It was approximately $2.4 \mathrm{~m}$ by $2.0 \mathrm{~m}$ in size. The base of this artificial surface was made from two large plywood boards, on which two-by-four (approximately $3.6 \mathrm{~cm} \times 8.6 \mathrm{~cm}$ cross-sectional area) lumber and plywood board cuts were placed to make eight Artificial Channels (AC), mimicking the channel types observed in the field (Table 1). The ACs were divided into two major groups: the U-channels and V-channels. For the U-channels, width and depth were kept constant along the channels. In order to test the impact of size and shape, three types of U-channels were installed: regular (10.0 cm wide and $3.9 \mathrm{~cm}$ deep), deep (10.0 cm wide and $7.6 \mathrm{~cm}$ deep), and wide $(20.1 \mathrm{~cm}$ wide and $3.9 \mathrm{~cm}$ deep) U-channel, respectively. For the V-channels, they were shaped to tape off at one end and, therefore, the width (from $0 \mathrm{~cm}$ to $\sim 24 \mathrm{~cm}$ ) and depth (from $0 \mathrm{~cm}$ to $\sim 15 \mathrm{~cm}$ ) varied along the length of the channels. The design of the V-channel provided the possibility to examine the effects of channel size. In addition, to test the influences of channel orientation on the accuracy, channels were installed in three orientations, referred to as vertical, angled, and horizontal channel.

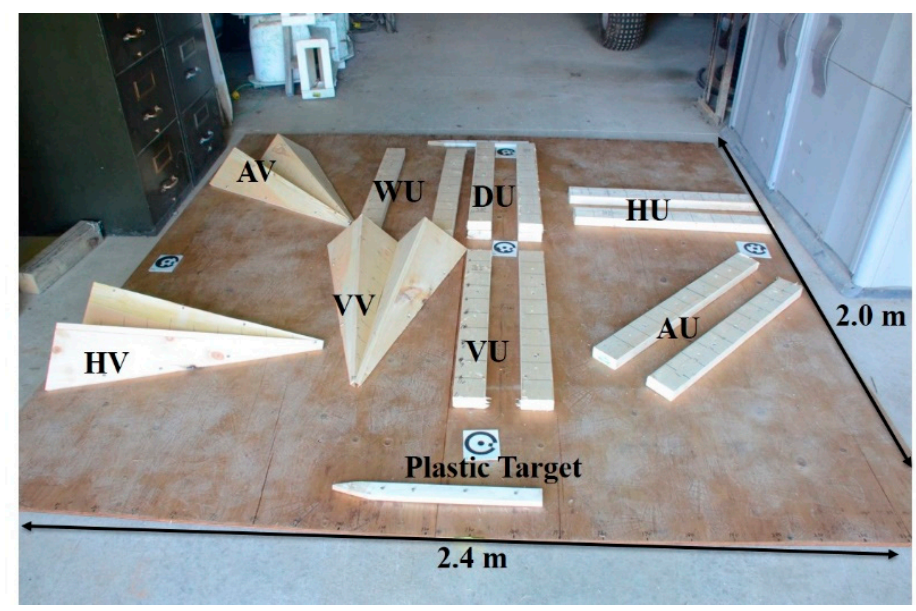

Figure 1. Artificial surface used in this study.

Table 1. Characteristics of artificial channels on the artificial surface.

\begin{tabular}{ccccccccc}
\hline Acronym & VU & AU & HU & DU & WU & VV & AV & HV \\
\hline Shape & U-shape & U-shape & U-shape & U-shape & U-shape & V-shape & V-shape & V-shape \\
Orientation & Vertical & Angled & Horizontal & Vertical & Vertical & Vertical & Angled & Horizontal \\
Size & Regular & Regular & Regular & Deep & Wide & N/A & N/A & N/A \\
\hline
\end{tabular}

The soil surface was located in the experimental farm. The field was located on an east-north facing slope with $\sim 10 \%$ slope gradient. The soil at the site is classified as Fredericton Orthic Humo-Ferric Podzol, and the surface soil is mostly sandy loam in texture [52]. The field was under terracing practice without any crop residue from the previous year. Therefore, the bare soil surface was susceptible to water erosion. In May 2019, a 3.5 m long rill (Figure 2) was created by snowmelt water on the upper slope area. Unlike the U-channels on the artificial surface, the size varied along the rill. The depth of the rill ranges from $0.05 \mathrm{~m}$ to $0.23 \mathrm{~m}$, while the width of the rill ranges from $0.30 \mathrm{~m}$ to $0.70 \mathrm{~m}$. The rill 
became wider and shallower at the downslope position. The soil surface, which is a rill, provided an opportunity to validate the performance of the CGC-CRP method for detecting the geometry of rills.

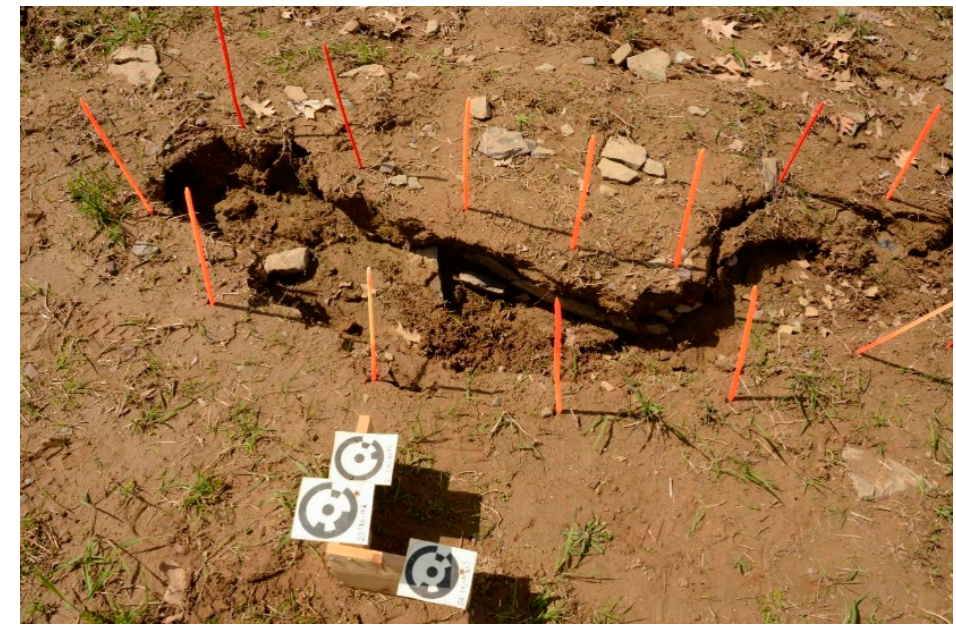

Figure 2. A portion of the water-induced channel on the soil surface. The red sticks along the side of the channel denote the locations for the cross-sections.

\subsection{Data Collection}

For the artificial surface, the cross-sectional area was calculated based on the width and depth measurements to characterize the geometry of ACs. The parameter was first collected manually and was then obtained using the CGC-CRP method with different settings. The manual measurement was used as the references (control), and the differences between the manual method and the CGC-CRP method were used to assess the errors associated with the CGC-CRP method. Similarly, for the soil surface, the cross-sectional area was first measured manually and was then assessed using the CGC-CRP method.

\subsubsection{Manual Measurement}

For the artificial surface experiment, maximum channel width and depth were measured manually using a measuring tape at 10 locations in $10 \mathrm{~cm}$ interval along each channel. The accuracy of the manual measurements was at approximately $1 \mathrm{~mm}$ level. At each location, the maximum channel width was measured at the top of the channel along a transect perpendicular to the length of the channel, and maximum channel depth was measured from a meter stick resting on the channel bank to the bottom of a U-channel or the wedging tip of a V-channel. The cross-sectional area was calculated from the measured width and depth values. For the U-channels, the differences between the ten locations were minimal, so parameters determined at the 10 locations were treated as repeated measurements, and the average values were used as the reference values characterizing the channel as a whole. For the V-channels, these parameters varied along the channel, so they were treated as individual measurements at each location.

For the soil surface experiment, ten pairs of plastic sticks were inserted on both sides of the channel to indicate the positions of the transect (Figure 2). The pairs of sticks were installed at an interval ranging from $0.2 \mathrm{~m}$ to $0.6 \mathrm{~m}$ along the channel. At each transect location, a straight ruler was placed at the top of the channel. The channel depth was measured from a vertical meter stick resting on the channel bottom to the straight ruler on the top. The depth measurement was recorded starting from the left side to the right side of the stick at $0.01 \mathrm{~m}$ interval along the transect. Each depth measurement represented the nearby one $\mathrm{cm}$ wide area. Therefore, the cross-sectional area $\left(\mathrm{in}^{2} \mathrm{~cm}^{2}\right)$ for each transect was calculated by summing all the depth measurements together. 


\subsubsection{Consumer-Grade Camera Based Photogrammetry (CGC-CRP)}

For the photogrammetry method, a Nikon D7000 camera (Table 2) and an AF-S Nikkor 18-200 mm $\mathrm{f} / 3.5-5.6 \mathrm{G}$ ED VR II lens were used in this study.

Table 2. Technical specifications of the camera used in this study (a Nikon D7000).

\begin{tabular}{cc}
\hline Tech Specs & \\
\hline Effective Pixels (Megapixels) & 16.2 million \\
Image Sensor Size (mm) & $23.6 \times 15.6$ \\
Image Sensor Format & $\mathrm{DX}$ \\
Image Sensor Type & CMOS \\
Total Pixels (Megapixels) & 16.9 million \\
Image Pixel Size ( $\mu \mathrm{m})$ & 4.78 \\
Image Area (pixels) & $4928 \times 3262$ \\
Approx. Weight $(\mathrm{g})$ & 690 \\
\hline
\end{tabular}

For the artificial surface, in order to assess the impact of different factors on channel detection, the camera position and shooting angle need to be stable throughout the test, so the camera was attached to an aluminum post at approximately $1.92 \mathrm{~m}$ above the ground, and the shooting angle was adjusted with a tripod adapter (Figure 3). The $1.92 \mathrm{~m}$ height was chosen because it is a height that is convenient to the operator and there is an original drilling hole at this height on the post. Before data collection, the lens was autofocused to the board surface firstly. Then, the camera was switched to the manual focusing mode so that the focusing distance will not change during one set of photo shooting. Calibration for lens interior orientation and lens distortion was performed by the PhotoModeler Scanner ${ }^{\circledR}$ software automatically using a built-in algorithm with multiple (more than 8) overlapped photos. The coordinate system and scale were defined using five plastic targets fixed on the board surface. Four of the five targets were placed at the middle point of each edge, and the last one was placed in the center of the board. The distance between the targets ranged from $0.9 \mathrm{~m}$ to $2.2 \mathrm{~m}$. Their locations were precisely measured with a measuring tape. These targets can be automatically detected by the software, facilitating fast data processing.

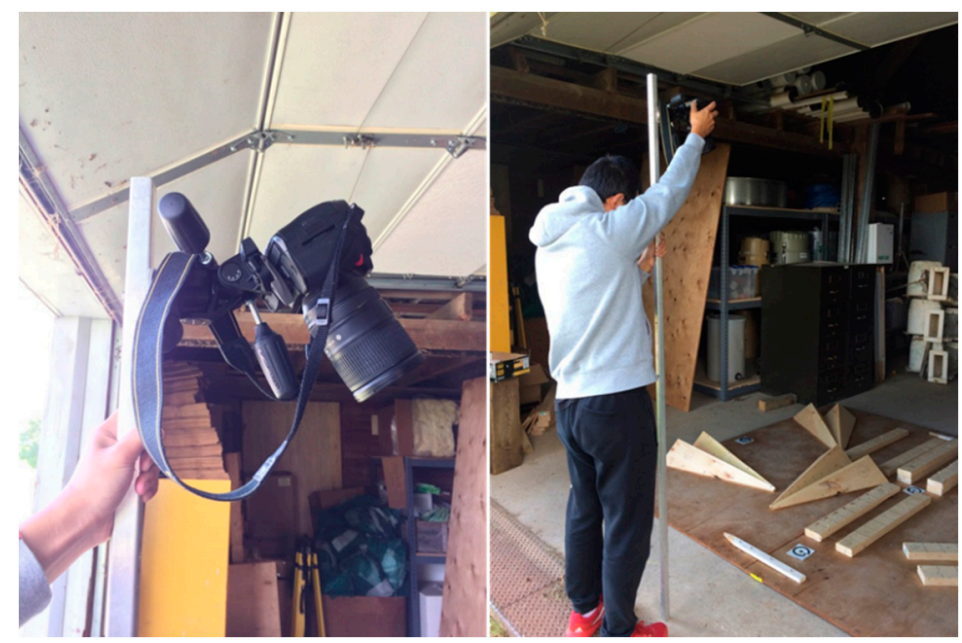

Figure 3. Setup of the camera used for the CGC-CRP method. The camera was attached to an aluminum post with adjustable shooing angles. The camera was $1.92 \mathrm{~m}$ above the ground.

All photos were taken along the two long edges of the board surface. For all photos, the photographer was located $\sim 0.2 \mathrm{~m}$ to $\sim 0.5 \mathrm{~m}$ away from the edges of the board, and the camera was facing toward the surface. Six shooting angle treatments $\left(90^{\circ}, 80^{\circ}, 70^{\circ}, 60^{\circ}, 45^{\circ}\right.$, and $\left.30^{\circ}\right)$ were applied. With each shooting angle, the first photo was taken at the corner of the board, then the photographer 
moved along the long edge, and subsequent photos were taken at $10 \mathrm{~cm}$ interval. The same procedure was repeated along the other edge for the other set of photos. In total, 26 photos were taken to cover the entire surface. With $10 \mathrm{~cm}$ interval, the image overlapping rate was $95 \%$. For testing the effect of overlapping rate, photos at $20 \mathrm{~cm}, 50 \mathrm{~cm}, 70 \mathrm{~cm}, 100 \mathrm{~cm}$, and $120 \mathrm{~cm}$ intervals were selected to make datasets with image overlapping rate of $90 \%, 80 \%, 70 \%, 60 \%$, and $50 \%$, respectively. For comparing different shooting angles, data with image overlapping rate of $80 \%$ was presented because it is a common overlapping rate used in the close-range photogrammetry [53]. For comparing different image overlapping rates, data with shooting angle of $70^{\circ}$ was presented because the $70^{\circ}$ shooting angle was found to perform the best in the above-mentioned shooting angle test. Moreover, it is a shooting angle can cover a relatively large area and is easy to operate by a photographer in the field.

For the soil surface, the consumer-grade camera was handheld by the photographer without any support post. Similarly, before data collection, the lens was autofocused to the channel. Then, the camera was switched to the manual focusing mode. The coordinate system was defined with a reference device placed on the ground. The device has three $15 \mathrm{~cm}$ long arms, which are perpendicular to each other, to form a coordinate system on its own. At the end of each arm, a target was installed. As the locations of the three targets are fixed and accurately measured, when the device was captured in the photo, it can be used as a reference for length and height measurement. All photos were taken along the two long edges of the channel. The photographer was located $\sim 0.3 \mathrm{~m}$ away from the edges, and the camera was facing toward the channel at $\sim 70^{\circ}$ shooting angle. The first photo was taken at the top of the channel, then the photographer moved along both sides of the channel, and subsequent photos were taken with $\sim 70 \%$ overlap.

\subsection{Data Extraction and Analysis}

For the CGC-CRP method, the raw data were photo images. These photo images were imported into PhotoModeler Scanner ${ }^{\circledR}$, which uses an algorithm based on the scale-invariant feature transform (SIFT) developed by Lowe [24] to extract point cloud with 3D coordinates information in $1 \mathrm{~mm}$ resolution. After the images were processed in PhotoModeler Scanner ${ }^{\circledR}$, more than 5,000,000 3D coordinates were extracted for each raw dataset.

The 3D coordinate data derived from PhotoModeler Scanner ${ }^{\circledR}$ were imported into Surfer ${ }^{\circledR}$, and the triangulation with linear interpolation method was used to generate grid format DEMs. The triangulation with linear interpolation method was selected because it is an exact interpolator, so it does not extrapolate beyond the elevation value of the data range, representing the real measured elevation values better [54]. All DEMs generated were in $1 \mathrm{~mm}$ resolution (cell size $=1 \mathrm{~mm}$ ). After the DEMs were generated, ten cross-sectional reference transects, matching those measured manually, were extracted from each AC or water-induced channel. The area of the cross section was obtained for each transect using a tool provided in Surfer ${ }^{\circledR}$. The accuracy of the method was assessed by comparing the value derived from the DEMs to the value derived from manual measurements.

For the U-channels of the artificial surface, the precision of the method was assessed using Standard Deviation (SD), Mean Error (SE), and Root Mean Square Error (RMSE), defined as follows,

$$
\begin{aligned}
\mathrm{SD} & =\sqrt{\frac{\sum_{\mathrm{i}=1}^{\mathrm{N}}\left(\mathrm{X}_{\mathrm{i}}-\overline{\mathrm{X}}\right)^{2}}{\mathrm{~N}}}, \\
\mathrm{ME} & =\frac{\sum_{\mathrm{i}=1}^{\mathrm{N}}\left(\mathrm{X}_{\mathrm{i}}-\mathrm{X}_{\text {Ref }}\right)}{\mathrm{N}}, \\
\mathrm{RMSE} & =\sqrt{\frac{\sum_{\mathrm{i}=1}^{\mathrm{N}}\left(\mathrm{X}_{\mathrm{i}}-\mathrm{X}_{\text {Ref }}\right)^{2}}{\mathrm{~N}}},
\end{aligned}
$$


where $X_{i}$ is the parameter value for the ith transect, $\bar{X}$ indicates the average parameter value of all $\mathrm{N}$ transects, and Ref denotes the reference value from manual measurements. It should be noted that the SD value was not applicable for the V-channels or the soil surface channel examined in this study because the area of cross section varied along the channel, so that all measurements are individual measurements and there were no repeats. Therefore, no mean or SD can be calculated.

\subsection{Applicability Measures}

The applicability of manual method and the CGC-CRP method on detecting channels were tested by comparing equipment, time consumption and detection area (Figure 4). The equipment needed and time consumption of each test were recorded during the experiments.

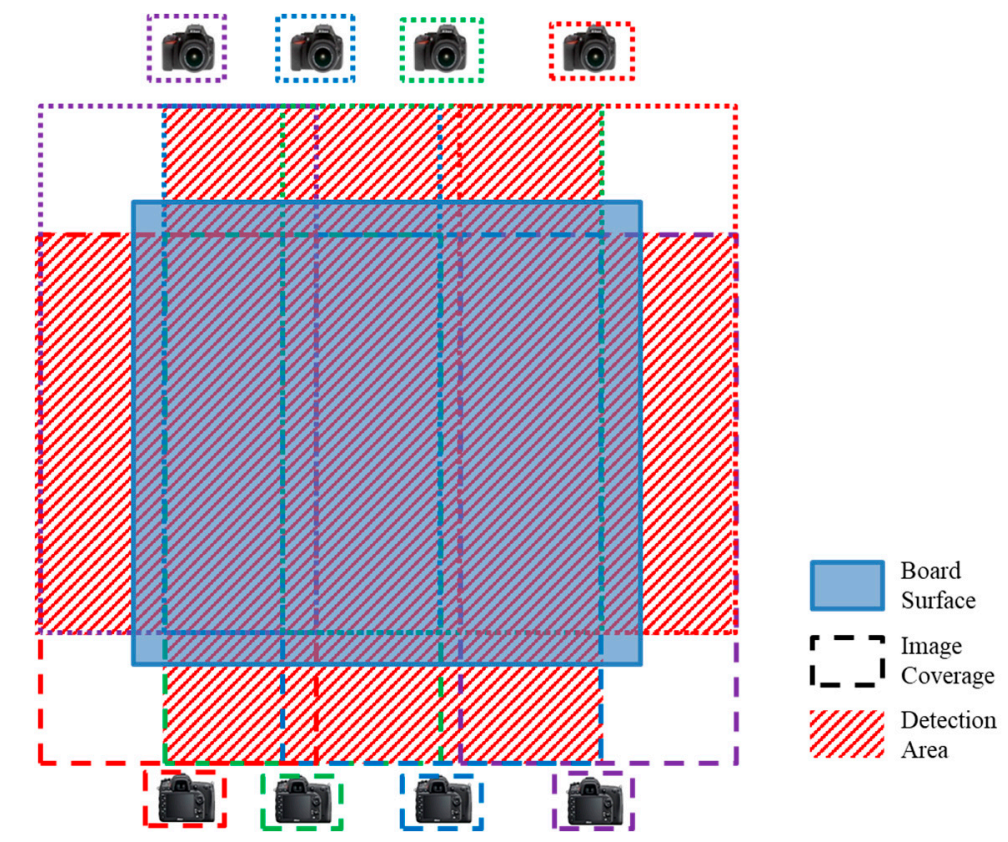

Figure 4. Illustration of the detection area for the CGC-CRP method (Top view, the dashed lines in different colors delineate the photo coverage area of each camera position, and the overlap of these areas is the detection area of the Digital Elevation Model (DEM)).

\section{Results}

\subsection{Artificial Surface}

\subsubsection{Visual Observation of the DEMs}

In all generated DEMs, all objects were clearly identifiable and in the correct locations (Figures 5 and 6). For camera shooting angle settings, there was a general trend of increasing noise with the decrease of shooting angle, whereas for image overlapping rate settings, there was a general trend of increasing noise with the decrease of image overlapping rate. At the lowest shooting angle $\left(30^{\circ}\right)$ and lowest image overlapping rates $(60 \%$ and $50 \%)$, some objects were significantly deformed. 


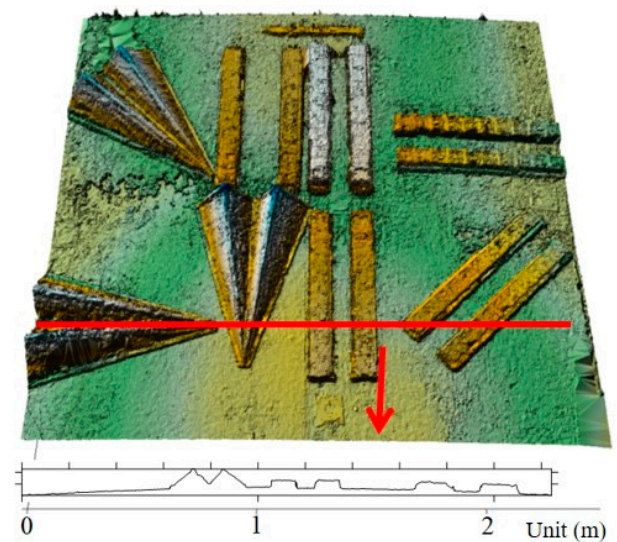

(a) CGC-CRP-90-80\%

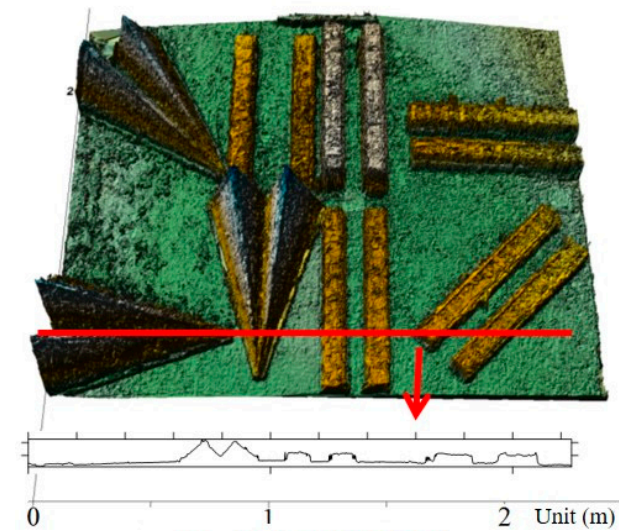

(c) CGC-CRP-70-80\%

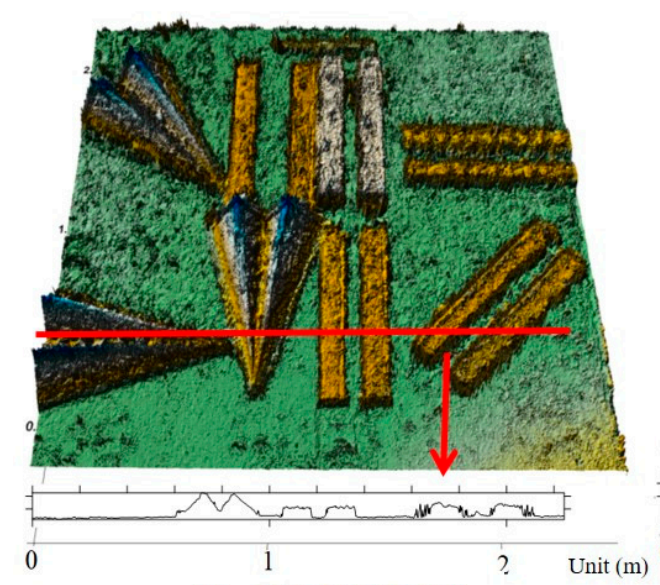

(e) CGC-CRP- $45-80 \%$

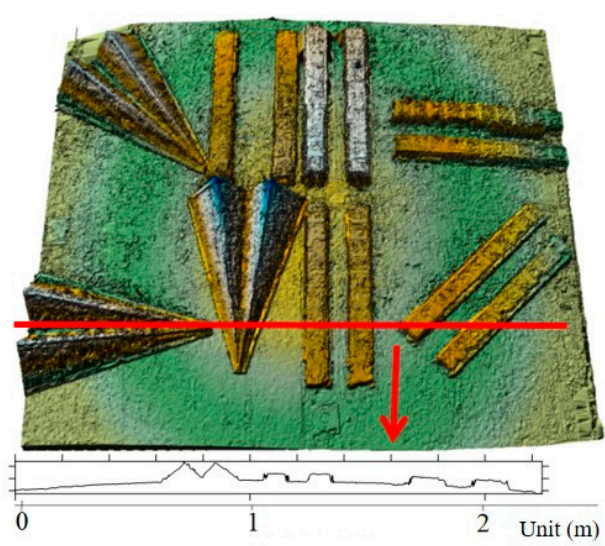

(b) CGC-CRP-80-80\%

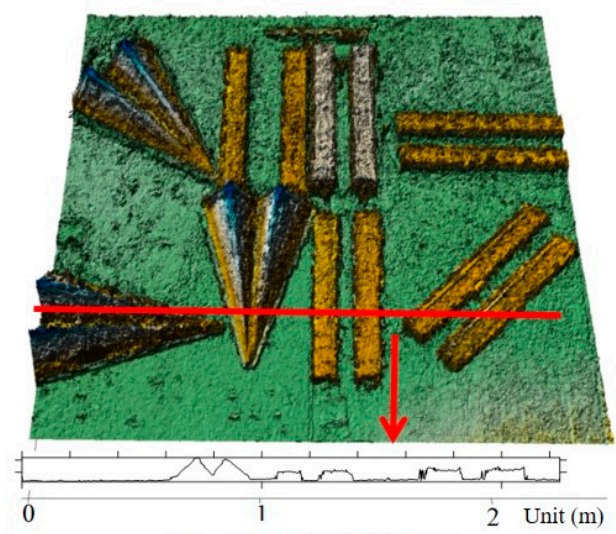

(d) CGC-CRP-60-80\%

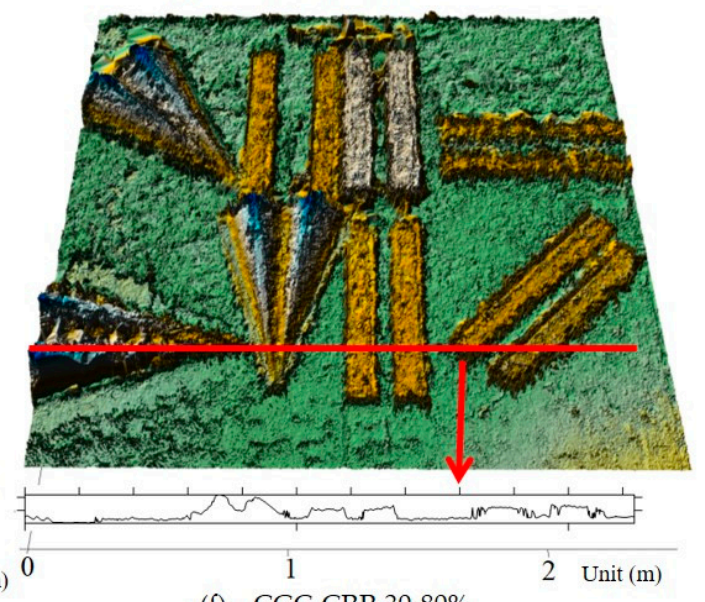

(f) CGC-CRP-30-80\%
Height $/ \mathrm{m}$

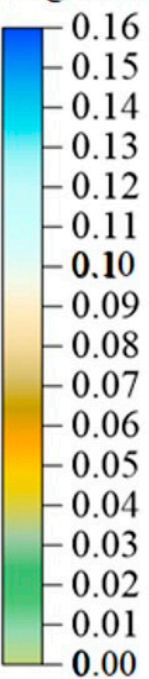

0.00

Figure 5. Maps generated from DEMs obtained using the CGC-CRP method with different camera shooting angle settings, (a) $90^{\circ}$, (b) $80^{\circ}$, (c) $70^{\circ}$, (d) $60^{\circ}$, (e) $45^{\circ}$, and (f) $30^{\circ}$, with an overlapping rate of $80 \%$. An example transect extracted from each DEM was shown at the bottom of the map. 


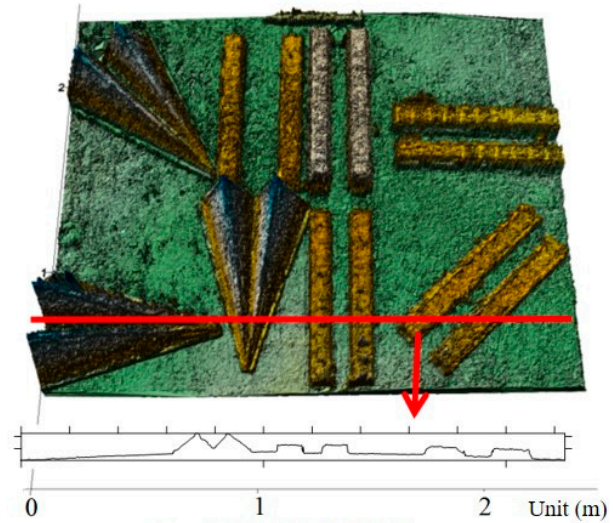

(a) CGC-CRP-70-90\%

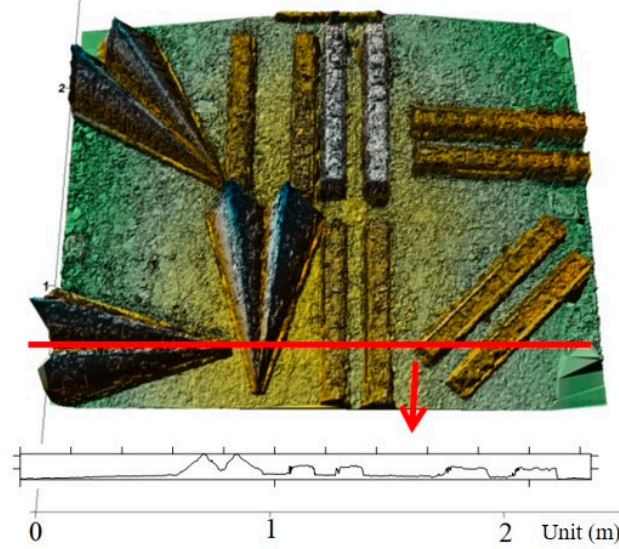

(c) CGC-CRP-70-70\%

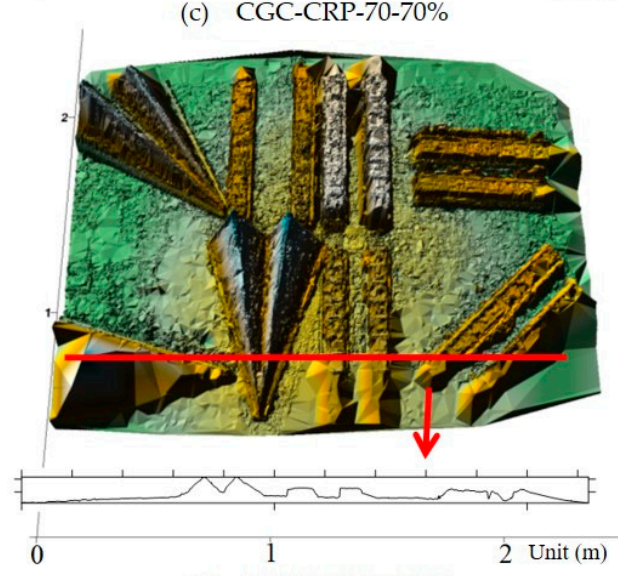

(e) CGC-CRP-70-50\%

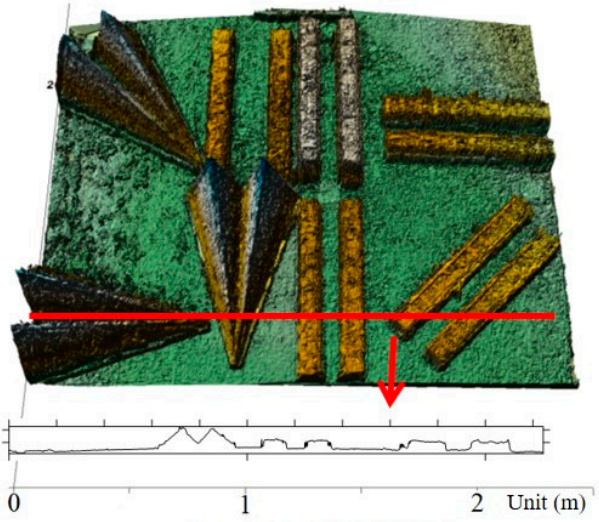

(b) CGC-CRP-70-80\%

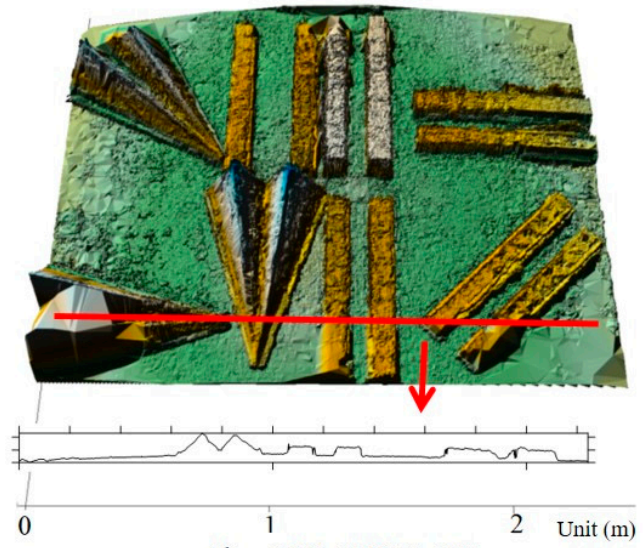

(d) CGC-CRP-70-60\%
Height $/ \mathrm{m}$

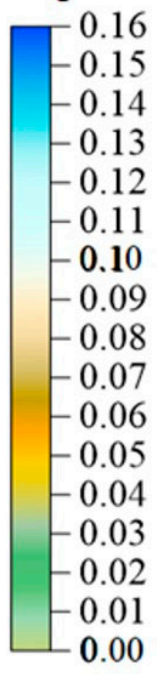

$-0.15$

0.14

0.13

0.12

0.10

0.09

0.07

0.06

0.03

0.02

0.00

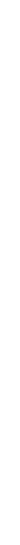

Figure 6. Maps generated from DEMs obtained using the CGC-CRP method with different image overlapping rate settings, (a) $90 \%$, (b) $80 \%$, (c) $70 \%$, (d) $60 \%$, and (e) $50 \%$, with a shooting angle of $70^{\circ}$. An example transect extracted from each DEM was shown at the bottom of the map.

\subsubsection{U-Channels}

For U-channel objects, the channel size maintained the same for each individual object so that the cross-sectional area measurements can be considered repeated measurements. For the vertically oriented U-channel (VU), manually measured cross-sectional area averaged at $39.0 \mathrm{~cm}^{2}$ with a CV of $1.4 \%$. The CGC-CRP-derived area with $70^{\circ}$ shooting angle and $80 \%$ overlapping rate (Table 3 ) ranged from $25.5 \mathrm{~cm}^{2}$ to $36.2 \mathrm{~cm}^{2}$, and averaged at $31.0 \mathrm{~cm}^{2}$ with a SD of $3.4 \mathrm{~cm}^{2}$, a ME of $-8.0 \mathrm{~cm}^{2}$ and a RMSE of $8.6 \mathrm{~cm}^{2}$. 
Table 3. Average, standard deviation (SD), mean error (ME), and root mean square error (RMSE) of the cross-sectional area ( $\mathrm{cm}^{2}$ ) of selected transects derived from the CGC-CRP method for U-channels on the artificial surface.

\begin{tabular}{|c|c|c|c|c|c|c|c|c|c|c|c|c|}
\hline \multirow{2}{*}{ Channel } & & \multicolumn{6}{|c|}{ Shooting Angle (with $80 \%$ Overlap) } & \multicolumn{5}{|c|}{ Image Overlap Rate (with $70^{\circ}$ Angle) } \\
\hline & & $90^{\circ}$ & $80^{\circ}$ & $70^{\circ}$ & $60^{\circ}$ & $45^{\circ}$ & $30^{\circ}$ & $90 \%$ & $80 \%$ & $70 \%$ & $60 \%$ & $50 \%$ \\
\hline \multirow{4}{*}{ VU } & Average & 29.0 & 30.0 & 31.0 & 28.6 & 27.0 & 21.3 & 27.4 & 31.0 & 26.9 & 25.8 & 20.4 \\
\hline & SD & 3.8 & 1.2 & 3.4 & 3.7 & 3.6 & 5.6 & 2.9 & 3.4 & 3.8 & 3.3 & 13.6 \\
\hline & ME & -10.0 & -9.0 & -8.0 & -10.4 & -12.0 & -17.7 & -5.5 & -8.0 & -12.1 & -13.1 & -18.6 \\
\hline & RMSE & 10.6 & 9.0 & 8.6 & 10.9 & 12.5 & 18.5 & 6.1 & 8.6 & 12.6 & 13.5 & 22.4 \\
\hline \multirow{4}{*}{$\mathbf{A U}$} & Average & 26.7 & 27.3 & 28.6 & 30.6 & 27.9 & 19.6 & 24.6 & 28.6 & 29.0 & 27.2 & 13.8 \\
\hline & SD & 4.9 & 3.5 & 2.9 & 3.1 & 13.0 & 9.2 & 3.5 & 2.9 & 2.0 & 4.7 & 7.1 \\
\hline & ME & -14.4 & -13.8 & -12.4 & -10.6 & -13.2 & 21.4 & -9.7 & -12.4 & -12.0 & -14.0 & -27.4 \\
\hline & RMSE & 15.1 & 14.3 & 12.7 & 11.0 & 18.0 & 23.2 & 10.3 & 12.7 & 12.2 & 14.7 & 28.3 \\
\hline \multirow{4}{*}{ HU } & Average & 28.4 & 25.5 & 33.1 & 34.6 & 22.4 & 18.0 & 27.3 & 33.1 & 34.0 & 24.6 & 18.7 \\
\hline & $\mathrm{SD}$ & 5.1 & 3.4 & 3.0 & $7 . .8$ & 7.6 & 9.9 & 3.3 & 3.0 & 2.9 & 7.4 & 11.8 \\
\hline & ME & -10.4 & -13.4 & -5.7 & -4.2 & -16.4 & -20.8 & -3.4 & -5.7 & -4.8 & -14.2 & -20.1 \\
\hline & RMSE & 11.6 & 13.8 & 6.3 & 8.4 & 17.8 & 22.7 & 4.7 & 6.3 & 5.5 & 16.0 & 23.1 \\
\hline \multirow{4}{*}{ DU } & Average & 60.6 & 56.5 & 52.1 & 63.4 & 55.0 & 44.5 & 64.5 & 52.1 & 48.8 & 50.6 & 72.3 \\
\hline & SD & 4.9 & 4.5 & 4.0 & 8.5 & 6.3 & 12.0 & 3.1 & 4.0 & 2.9 & 4.4 & 27.4 \\
\hline & ME & -17.8 & -21.8 & -26.3 & -14.9 & -23.4 & -33.7 & -22.3 & -26.3 & -29.6 & -27.8 & -6.5 \\
\hline & RMSE & 18.2 & 22.1 & 26.5 & 17.0 & 24.1 & 35.5 & 22.6 & 26.5 & 29.7 & 28.2 & 27.0 \\
\hline \multirow{4}{*}{ WU } & Average & 64.8 & 59.9 & 62.8 & 67.0 & 72.2 & 65.6 & 64.7 & 62.8 & 66.7 & 63.6 & 49.7 \\
\hline & $\mathrm{SD}$ & 3.0 & 2.5 & 3.0 & 9.4 & 6.8 & 16.7 & 2.8 & 3.0 & 5.0 & 3.7 & 11.9 \\
\hline & ME & -9.6 & -18.1 & -15.2 & -11.0 & -5.6 & -12.4 & -8.4 & -15.2 & -11.2 & -14.4 & -28.3 \\
\hline & RMSE & 13.5 & 18.4 & 15.6 & 14.0 & 8.8 & 19.9 & 9.0 & 15.6 & 12.4 & 14.7 & 30.6 \\
\hline
\end{tabular}


With respect to the different shooting angle setting, $70^{\circ}$ shooting angle (Table 3 ) appears to have the lowest SD (except for comparing to $80^{\circ}$ shooting angle), ME, and RMSE values. From the $70^{\circ}$ shooting angle, increasing and decreasing of shooting angle both led to increasing SD (except for the $80^{\circ}$ shooting angle), ME, and RMSE values. When the shooting angle is low, the angle of view to the ground surface is narrow, which increases the coverage area on the ground captured by the image but reduces its resolution. With fewer points representing the same area, the accuracy is expected to be lower. However, the situation is different for the channel walls. Because the wall is perpendicular to the ground surface, when the shooting angle is high, the angle of view towards the channel wall is narrow, resulting in a shorter length for the height of the wall on the image and, therefore, fewer points on the wall that can be captured by the photogrammetry. A $70^{\circ}$ shooting angle appears to be the best shooting angle setting because it balances the errors for the ground surface and those for the channel walls. From $70^{\circ}$, reducing the shooting angle appears to reduce the accuracy of the photogrammetry more than increasing the shooting angle. When the shooting angle dropped from $45^{\circ}$ to $30^{\circ}$, there were substantial drops in SD, ME, and RMSE values.

With respect to the image overlapping rate setting, SD, ME, and RMSE all increase with decreasing image overlapping rate, which is expected. In particular, when the overlapping rate dropped from $60 \%$ to $50 \%$, there were substantial drops in SD, ME, and RMSE values (Table 3). It should be noted that ME values for all settings were negative, indicating that there was always an underestimation of the cross-sectional area. This could be explained by that it is hard to capture the corner of the channel, which was artificially made at a $90^{\circ}$ angle. In fact, under all settings, the channels on the DEMs had more or less a trapezoidal shape, with the corners cut out.

For the Angled U-channel (AU) and the Horizontal U-channel (HU), the trends of accuracy measurements (SD, ME, and RMSE) with camera shooting angle and image overlapping rate were almost the same as those for the VU. Moreover, for both AU and HU, the ME values for all settings were negative, the same as for VU. However, substantial drop in accuracy for the shooting angle occurred from $60^{\circ}$ to $45^{\circ}$ for both $\mathrm{AU}$ and $\mathrm{HU}$, and also from $70^{\circ}$ to $80^{\circ}$ for $\mathrm{HU}$ whereas the substantial drop in accuracy for the overlapping rate occurred from $60 \%$ to $45 \%$ for AU (the same as for VU) and $70 \%$ to $60 \%$ for HU (Table 3). This suggested that the camera shooting angle needs to be between $60^{\circ}$ and $80^{\circ}$ and the image overlapping rate needs to be $\geq 70 \%$ to maintain an acceptable level of accuracy. For AU, with only a few exceptions, the absolute values of SD, ME, and RMSE were greater than those for VU and HU, indicating a low accuracy with AU than with VU and HU (Table 3). This could be due to fact that the coordinate axes of the DEM were set up along the vertical and horizontal directions, and, as such, measurements along these two directions on the DEM were more direct. Measurements along diagonal directions require interpolation and, therefore, often have higher errors.

For the Deep U-channel (DU) and Wide U-channel (WU), the trend of SD measurements with camera shooting angle and image overlapping rate were similar to those for the VU. However, the trend of ME and RMSE measurements was different. For both DU and WU, these two measurements increased as the shooting angle dropped from $90^{\circ}$ to $70^{\circ}$. A substantial decrease in measurements (ME and RMSE) for the shooting angle was occurred at $60^{\circ}$ and $45^{\circ}$ for DU and WU, respectively. Below those angles, the measurements (ME and RMSE) of both DU and WU experienced an increase again. Besides, unlike VU, these two accuracy measurements fluctuate with a decreasing image overlapping rate (Table 3). These different trends observed from the DU and WU are hard to explain. Further investigation might be required to understand the details. As the cross-sectional area of Regular U-channel (VU) was only half of that of Deep U-channel (DU) and Wide U-channel (WU), so the ratio between the absolute $\mathrm{ME}$ and true value was a reasonable accuracy parameter for comparing the different channel sizes. A higher ratio indicates a lower accuracy. The ratio of DU was the highest for the shooting angle that occurred from $90^{\circ}$ to $70^{\circ}$, whereas that of WU was the smallest. Meanwhile, the ratio of VU was at a similar level as that of DU. This could be explained by that when the shooting angle is relatively high, the angle of view towards the ground surfaces of both DU and VU was narrow; therefore, fewer points on the ground surface could be captured by the photogrammetry, leading to 
low accuracy of DU and VU. In contrast, the ground surface of WU was wide, leading to the relatively high accuracy of WU. When shooting angle was from $60^{\circ}$ to $30^{\circ}$, the accuracy of DU became higher than those of $\mathrm{VU}$, probably because with a relatively low shooting angle, the angle of view towards the channel wall was wide; therefore, more channel wall area of DU could be captured than that of VU by the photogrammetry. Therefore, DU had a higher accuracy level than VU. With respect to the image overlapping rate, the ratio followed the order of $\mathrm{DU}>\mathrm{VU}>\mathrm{WU}$ for most cases. This could be rooted from that the default shooting angle $\left(70^{\circ}\right)$ was relatively high. Therefore, the photogrammetry was easier to capture the ground surface than the channel wall. As a result, the accuracy of WU was better than that of DU.

\subsubsection{V-Channels}

For V-channel objects, the channel size changed along the channel so that the cross-sectional area measurements varied. For the vertically oriented V-channel (VV), the manual measurements of the cross-sectional area (Table 4 ) ranged from $0.1 \mathrm{~cm}^{2}$ to $113.9 \mathrm{~cm}^{2}$, whereas the CGC-CRP-derived value with $70^{\circ}$ shooting angle and $80 \%$ overlapping rate ranged from $0.0 \mathrm{~cm}^{2}$ to $114.2 \mathrm{~cm}^{2}$. Unlike the U-channel, there was no systematic under- or overestimation with the V-channel (Figure 7). Moreover, the absolute values of error for V-channel were approximately $15 \%$ less than those of U-channel. This could be rooted from that the sidewalls of $\mathrm{V}$-channel were angled, not straight down and perpendicular to the ground. Therefore, the errors due to cutting out corners were expected to be much lower.

Table 4. ME and RMSE of the cross-sectional area $\left(\mathrm{cm}^{2}\right)$ of selected transects derived from the CGC-CRP method for V-channels on the artificial surface.

\begin{tabular}{ccccccccccccc}
\hline \multirow{2}{*}{ Channel } & & \multicolumn{4}{c}{ Shooting Angle (with 80\% Overlap) } & \multicolumn{4}{c}{ Image Overlap Rate (with 70 ${ }^{\circ}$ Angle) } \\
& & $\mathbf{9 0}^{\circ}$ & $\mathbf{8 0}^{\circ}$ & $\mathbf{7 0}^{\circ}$ & $\mathbf{6 0}^{\circ}$ & $\mathbf{4 5}^{\circ}$ & $\mathbf{3 0}^{\circ}$ & $\mathbf{9 0} \%$ & $\mathbf{8 0} \%$ & $\mathbf{7 0 \%}$ & $\mathbf{6 0} \%$ & $\mathbf{5 0 \%}$ \\
\hline \multirow{2}{*}{ VV } & ME & 1.5 & -0.8 & -0.6 & 6.2 & 5.1 & 4.8 & 2.3 & -0.6 & 0.2 & 0.1 & -1.5 \\
& RMSE & 2.7 & 3.0 & 1.3 & 10.4 & 8.3 & 8.6 & 4.0 & 1.3 & 1.9 & 2.4 & 2.4 \\
\hline \multirow{2}{*}{ AV } & ME & 3.8 & -0.4 & -0.4 & 9.2 & 3.8 & -12.9 & 4.5 & -0.4 & 3.6 & -8.4 & -3.7 \\
& RMSE & 4.9 & 5.1 & 1.6 & 12.7 & 9.1 & 18.3 & 5.6 & 1.6 & 5.7 & 7.9 & 21.8 \\
\hline \multirow{2}{*}{$\mathbf{H V}$} & ME & -2.5 & -5.5 & -6.2 & 9.2 & 6.0 & -1.6 & 7.5 & -6.2 & -5.5 & N/A & N/A \\
& RMSE & 9.3 & 8.9 & 8.9 & 11.9 & 8.4 & 19.0 & 9.7 & 8.9 & 7.0 & N/A & N/A \\
\hline
\end{tabular}

With respect to the different shooting angle settings, the accuracy measurements of VV showed a similar trend as those for the U-channel. The $70^{\circ}$ shooting angle appears to have the lowest absolute ME and RMSE values for VV. For different image overlapping settings, the absolute values of ME and RMSE for VV experienced a slight decrease with overlapping rate dropping from $90 \%$ to $70 \%$, but increased slightly again when the overlapping rate was less than $70 \%$. However, the largest discrepancy of the RMSE was only $1.7 \mathrm{~cm}^{2}$ (Table 4).

With respect to the different channel orientations, for the Angled V-channel (AV) and the Horizontal $\mathrm{V}$-channel (HV), the trends of ME and RMSE with camera shooting angle were similar to those for the VV in most cases. However, the RMSE values for both AV and HV were mostly double or triple of those for VV (Table 4). For the overlapping rate, unlike VV, a substantial drop in accuracy was observed from $60 \%$ to $50 \%$ for $\mathrm{AV}$, and for $\mathrm{HV}$, the V-channels were not well-formed in the DEMs (Table 4; Figure 6). This result suggested that, with a low image overlapping rate, the orientation affected the accuracy significantly. Overall, the results also suggest that the camera shooting angle needs to be $\geq 70^{\circ}$ and the image overlapping rate needs to be $\geq 60 \%$ to maintain a high level of accuracy. 

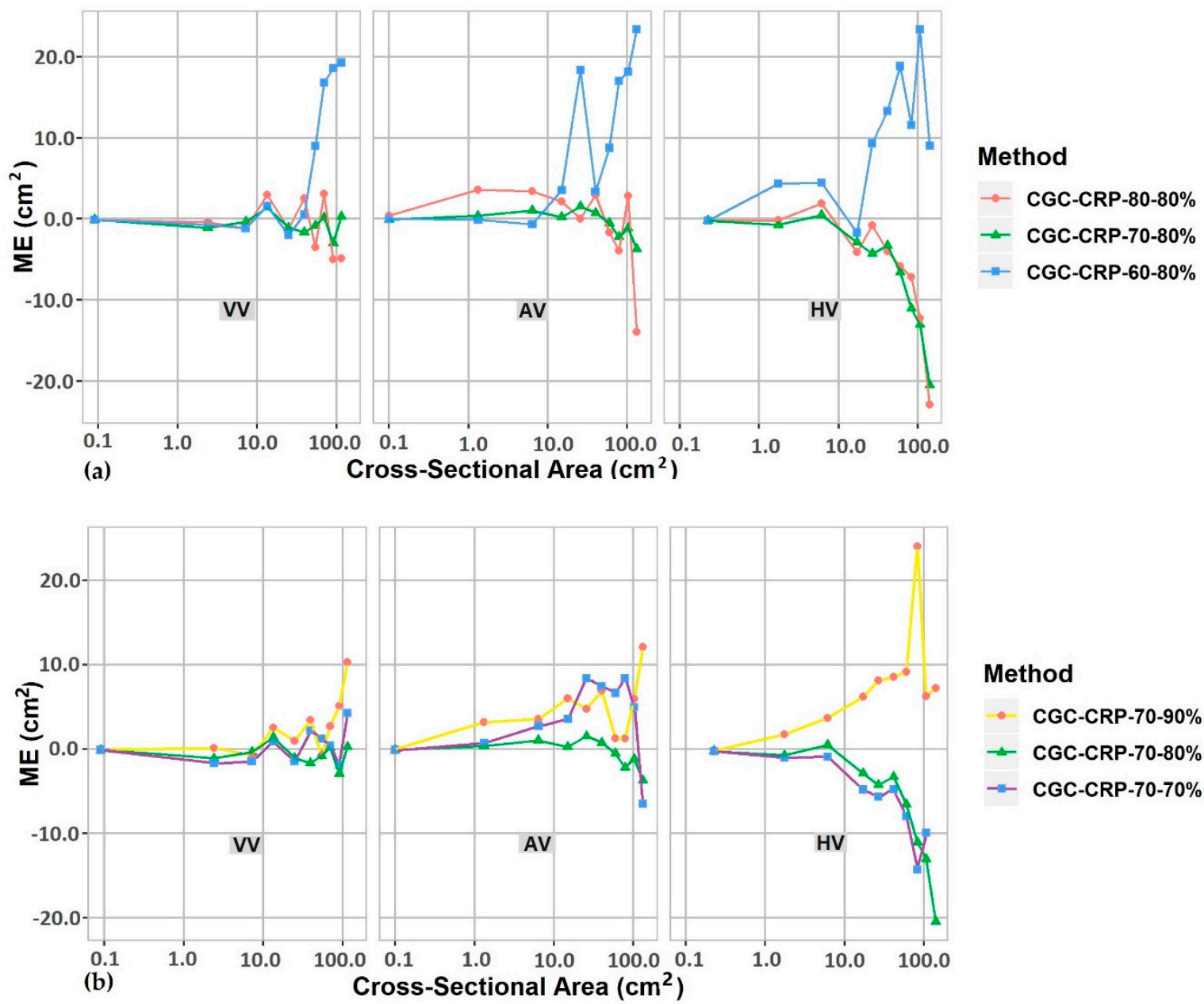

Figure 7. Mean error (ME) of cross section area $\left(\mathrm{cm}^{2}\right)$ derived from the CGC-CRP method with (a) selected camera shooting angle settings and (b) selected image overlapping rate settings. The $x$-axis is in logarithmic scale. VV: vertical channel, AV: angled channel, HV: horizontal channel.

With respect to channel size, for the VV with $70^{\circ}$ shooting angle and $80 \%$ image overlapping rate, the ME value was close to 0 when the cross-sectional area was less than $10 \mathrm{~cm}^{2}$. When the cross-sectional area was greater than $10 \mathrm{~cm}^{2}$, the ME value ranged from $-3.0 \mathrm{~cm}^{2}$ to $1.4 \mathrm{~cm}^{2}$ (Figure 7). This trend indicated that the accuracy was maintained at a high level under this setting, and the channel size did not have a significant impact on the accuracy level. However, when the shooting angle increased or decreased from $70^{\circ}$, the ME values became higher when the cross-sectional area was greater than $10 \mathrm{~cm}^{2}$. Moreover, in most cases, the ME values increased with increasing channel size. In addition, the channel orientation had an impact on the ME values. The ME values followed the order of $\mathrm{HV}>\mathrm{AV}>\mathrm{VV}$ for all settings (Figure 7). This could be explained by the shade effect. In the experiment, the source of the light was perpendicular but angled towards the direction of HV. As a result, there were shades on HV. There were also shades on AV, but the sizes were smaller. In addition, the width of the shade varied with channel size. This also explains why the error decreased with a decreasing channel size.

Based on the results of both U-channel and V-channel derived from the artificial surface test, we suggest using a $70^{\circ}$ shooting angle and $\geq 70 \%$ image overlapping rate because these settings could obtain acceptable levels of accuracy for both U- and V-channel in different orientations. Therefore, this setting was applied for the soil surface validation test below. 


\subsection{Soil Surface}

For the soil surface, manually measured cross-sectional areas for the ten transects ranged from $376.2 \mathrm{~cm}^{2}$ to $853.1 \mathrm{~cm}^{2}$, whereas the values derived from the CGC-CRP methods ranged from 385.9 $\mathrm{cm}^{2}$ to $877.9 \mathrm{~cm}^{2}$ (Table 5, Figure 8). There was no systematic under- or overestimation. The ME ranged from $-7.8 \mathrm{~cm}^{2}$ to $17.7 \mathrm{~cm}^{2}$, which can be translated to $-1.6 \%$ to $3.1 \%$ of the measurement. The overall RMSE for the ten transects was $8.6 \mathrm{~cm}^{2}$, which could be translated to $\sim 1.6 \%$ of the averaged cross-sectional area. This agrees with Castillo et al. [42], who reported that close-range photogrammetry and total station methods could produce cross-sectional area values with an error less than $4 \%$.

Table 5. Error and RMSE of cross-section area $\left(\mathrm{cm}^{2}\right)$ of selected transects derived from the CGC-CRP method for the water-induced channel on the soil surface.

\begin{tabular}{|c|c|c|c|c|c|c|c|c|c|c|c|c|}
\hline Transect & 1 & 2 & 3 & 4 & 5 & 6 & 7 & 8 & 9 & 10 & Average & RMSE $\left(\mathrm{cm}^{2}\right)$ \\
\hline $\begin{array}{c}\text { Manual } \\
\text { measurement }\end{array}$ & 482.0 & 506.2 & 498.8 & 480.1 & 376.2 & 487.1 & 489.7 & 853.1 & 749.1 & 537.4 & & \\
\hline $\operatorname{ME}\left(\mathrm{cm}^{2}\right)$ & 6.8 & 4.2 & -7.5 & -3.9 & 11.7 & 0.2 & -7.8 & 17.7 & -7.3 & 6.0 & 2.0 & 8.6 \\
\hline ME (\%) & 1.4 & 0.8 & -1.5 & -0.8 & 3.1 & 0.0 & -1.6 & 2.1 & -1.0 & 1.1 & 0.3 & \\
\hline
\end{tabular}

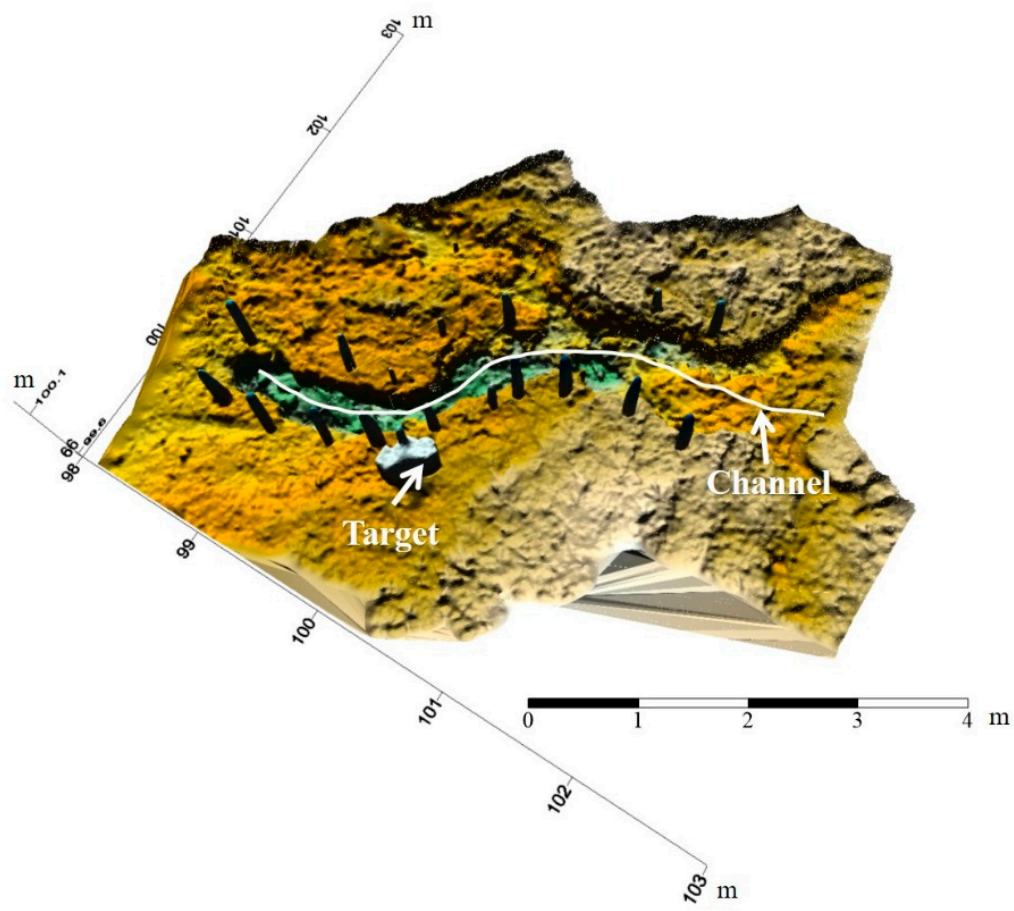

Figure 8. The map of soil surface channel produced from the DEM derived from the CGC-CRP method.

In comparison to the board surface test, the accuracy of the soil surface test was much higher. This could be explained by the lack of pattern contrast on the artificial surface. For the artificial surface, the channels were made from wood board and lumbers which were white in color. There was no clear pattern observed on these materials. As a result, the photogrammetric software was unable to pick out matching points in adjacent images correctly or obtain enough matching points, which led to higher errors. With the real soil surface, the pattern of soil particles and aggregates was clearly identifiable so that it was very easy for the software to find matching points. Therefore, the accuracy of channels on the real soil surface was much higher than that for the artificial surface. In other words, the accuracy measures derived from the artificial surface can be considered as the worst scenario values when using the CGC-CRP for real soil surface morphology measurement. 


\subsection{Applicability Analysis}

A reasonably good quality consumer-grade camera is the major equipment used with the CGC-CRP method. The price varies with brand and region but is not very expensive. The one used in this study was approximately $\$ 800$. The dimension of the camera was $132 \times 105 \times 77 \mathrm{~mm}$, and the weight was $\sim 690 \mathrm{~g}$, which makes it easy to carry in a field tour. Moreover, with modern technology, camera adjustment is largely automatic, so no sophisticated photo shooting skills are required for taking a clear picture. The camera used in this study can be operated in various weather conditions.

With respect to time consumption, for all settings, it took no more than $15 \mathrm{~min}$ to finish raw data collections (Table 6$)$. However, it took much longer $(\sim 2 \mathrm{~h})$ for data processing. The detection area of the CGC-CRP method varied with the settings (Table 6). However, there was a trade-off between the detection area and accuracy. The detection area increased but accuracy decreased with the decrease of shooting angle. On the other hand, with a lower overlapping rate, the detection area increased but the accuracy decreased substantially.

Table 6. Different settings and application information of the CGC-CRP method.

\begin{tabular}{cccc}
\hline $\begin{array}{c}\text { Shooting } \\
\left.\text { Angle } \mathbf{(}^{\circ}\right)\end{array}$ & $\begin{array}{c}\text { Image Overlapping } \\
\text { Rate }(\mathbf{\%})\end{array}$ & $\begin{array}{c}\text { Data Collection Time } \\
(\mathbf{m i n})\end{array}$ & $\begin{array}{c}\text { Detection Area Limit } \\
\left(\mathbf{m}^{\mathbf{2}} \mathbf{)}\right.\end{array}$ \\
\hline 90 & 80 & 13 & 3.6 \\
80 & 80 & 13 & 4.1 \\
70 & 80 & 13 & 5.5 \\
60 & 80 & 13 & 6.2 \\
45 & 80 & 13 & 10.8 \\
30 & 80 & 13 & 18 \\
70 & 90 & 15 & 5.5 \\
70 & 80 & 13 & 5.5 \\
70 & 70 & 10 & 5.5 \\
70 & 60 & 9 & 5.5 \\
70 & 50 & 8 & 5.5 \\
\hline
\end{tabular}

\section{Discussion}

\subsection{Guidance for Using a Consumer-Grade Camera to Measure Water-Induced Channels}

Results obtained from this study can be used to guide field measurement of water-induced channels using a consumer-grade camera. Lower shooting angle leading to lower accuracy in photogrammetry has been reported in many previous studies [45-47]. However, our results indicate that the optimum shooting angle ranges from $60^{\circ}$ to $80^{\circ}$, not $90^{\circ}$, and minor changes in shooting angle will not affect the accuracy significantly. This provides much flexibility for shooting angle setting. In fact, it is difficult to achieve a $90^{\circ}$ shooting angle or any other specific shooting angle. The range of $60^{\circ}$ to $80^{\circ}$ shooting angle allows the user to hold a camera in a relatively natural position. This range can be achieved by adjusting the height of the camera and the distance to the center of the area of interest. For example, if the photographer extends her or his arms and holds the camera $0.5 \mathrm{~m}$ away from the body, and $1.75 \mathrm{~m}$ above the ground, to achieve a shooting angle between $60^{\circ}$ and $80^{\circ}$, the photographer needs to stand 0.8-1.5 $\mathrm{m}$ away from the center of the area of interest while pointing the camera lens at it. Apparently, this range of distance will change when the position of the camera changes. However, a photographer can practice to hold the camera at a relatively fixed position based on her or his height and arm length. The parameters associated with this position $(0.5 \mathrm{~m}$ and $1.75 \mathrm{~m}$ in the previous example) can be measured before fieldwork and used to back calculate the range of distance between the photographer and the area of interest. The distance on the ground can be measured on site with a measuring tape. For image overlapping rate, it is also well known that the accuracy of photogrammetry increases with overlapping rate. Our study shows that enhancement in accuracy with increasing overlapping rate is limited when the overlapping rate is greater than $70 \%$. This sets a lower limit on the shifting distance 
from one photo to its adjacent photo. The shifting distance is determined by camera parameters and its position. Assuming we are using a Nikon 7000 with the focal length set at $18 \mathrm{~mm}$ and the camera is held at $1.75 \mathrm{~m}$ above the ground with a $75^{\circ}$ shooting angle, in order to obtain a $70 \%$ or greater overlapping rate, photos need to be taken at an interval less than $50 \mathrm{~cm}$. In other words, along the channel to be measured, the maximum distance we can move from one photo to its adjacent one is $50 \mathrm{~cm}$.

For camera setting, the focal length of the lens must be fixed in each survey. This is to ensure the proper calibration of camera distortion, which was done by the software automatically. For the software to quantify the distortion, it requires all paired photos to be taken at the same focal length. Fixed focal length sets the acceptable range of distance between the camera and the object (depending on the camera's depth of field), beyond which the picture will be blurry. This means that while taking multiple photos to make a DEM, the distance between the camera and the survey area needs to be kept the same as much as possible. However, this does mean that the focal length has to be kept the same all the time. Separate survey areas can use different focal lengths. Channel orientation also plays an essential role in controlling the measurement accuracy. For channel survey, taking photos from the upslope or downslope position while facing the channel vertically is the best. However, photos need to be taken from both sides of the channel to capture the walls better. Taking photos at a large angle or horizontally is not recommended as it may increase the measurement error. The CGC-CRP method can be used in various different weathers. However, bright sunshine is one of the weather conditions that needs to be avoided because it can create strong shadow effect. If the survey is conducted in a sunny day, shading the entire survey area might be necessary. Light rain and wind will not strongly affect the CGC-CRP survey. However, heavy rainfall and strong wind are to be avoided because most cameras are not waterproof and it is hard to hold the camera still in strong wind.

\subsection{Comparison to Other Methods}

For monitoring channelized erosion, the CGC-CRP method has several advantages over the traditional manual method (with rulers and measuring tapes). First, the CGC-CRP method requires much less time and labor in the field. In the soil surface survey conducted in the study, raw data collection in the field with the CGC-CRP method took less than five minutes as the operator only needed to take a series of photos, whereas for the traditional method, the fieldwork took two people one and a half hours. In this case, it was 36 times quicker with the CGC-CRP method. Saving fieldwork time is important because fieldwork is usually much more costly, time-sensitive, and demanding than office work, such as data analysis on a computer. Second, the CGC-CRP method can generate a DEM representing the whole detecting surface, whereas the traditional method only provides measurements for a limited number of cross-sectional areas. With a DEM, one can typically obtain more accurate channel volume measurements than with just cross-sectional area measurements because it needs interpolation to calculate channel volume. Moreover, with a DEM, one can extract many other valuable information (such as the sinuosity of the channel and the position of the thalweg in a channel).

The CGC-CRP method also has a few advantages over the aerial photogrammetry method on channel survey. First, the price of the major equipment used in the CGC-CRP method, a consumer-grade camera, is lower than the major equipment used in the aerial photogrammetry method (e.g., an UAV). Second, aerial photogrammetry is strongly affected by field conditions. For example, it is not recommended to be used in forested area for channel survey because an UAV is difficult to fly in the woods and if it is flying above the tree tops, the canopy and tree trunks will block the view [55-58]. Third, the use of the aerial photogrammetry method is restricted by weather conditions. It is usually very difficult to operate UAVs in windy or rainy conditions. In contrast, the effects of weather on the CGC-CRP method are minor, although it also has its limits as discussed in the previous session. Last, for the CGC-CRP method, the camera location is close to the detection surface (usually $<2 \mathrm{~m}$ ), whereas for the aerial photogrammetry, the camera is much further away (usually $>30 \mathrm{~m}$ ). Consequently, the resolution of the DEM derived from the CGC-CRP is typically much higher than those derived from 
the aerial photogrammetry. Higher resolution often leads to higher accuracy. However, the higher the location of the camera, the larger the detection area. Therefore, there is a trade-off between the detection area and accuracy. Compared to the CGC-CRP method, aerial photogrammetry can usually measure a much larger area in one run but its accuracy is often lower.

\subsection{Applications and Future Studies}

Our study showed that the CGC-CRP method is an easy-to-use method for topographic survey of a small area. The accuracy of CGC-CRP can reach the centimeter level. For different forms of erosion, sheet erosion is normally at the millimeter level (erosion rate of $10 \mathrm{Mg} \mathrm{ha}^{-1} \mathrm{yr}^{-1}$ is equivalent to $0.8 \mathrm{~mm} \mathrm{yr}^{-1}$ with a soil bulk density of $1250 \mathrm{~kg} \mathrm{~m}^{-3}$ ), so the CGC-CRP method may not be accurate enough and the traditional CRP method with more strict setup and error control is probably needed. However, centimeter accuracy is sufficient for rill and gully erosion studies, as rills and gullies are normally wider and deeper than $1 \mathrm{~cm}$. Many field surveyors carry a consumer-grade camera for their field trips so the equipment for the CGC-CRP method is readily available. This makes the CGC-CRP method well suited for any type of field survey. It can be a survey designed for monitoring erosion channels, a soil survey or a reconnaissance type of survey for any geoscience or environment-related topics.

The robustness of the CGC-CRP method also makes it particularly suited for some special conditions (e.g., limiting weather conditions or vegetation conditions making it difficult for other methods). For example, in Atlantic Canada, a critical time for gully erosion in agricultural fields is the snowmelt period in early spring. There is a short time window for measuring those gullies. However, in this time period, fields are wet and hard to walk on so that it is hard to carry heavy equipment into the field. This makes it very difficult for the use of terrestrial Lidar. Moreover, rainy and windy days are common in this period, which limits the applicability of the aerial photogrammetry and other airborne remote sensing methods. Further, as mentioned in the previous session, the CGC-CRP method is uniquely suited for channel survey in forested areas.

The discussion for the use of the CGC-CRP method is focused on measuring channelized erosion in this study. However, the method can be used to measure the shape and size of any objects. There are many other uses (e.g., archaeology and biology) for this method. The objects studied in other disciplines are diverse in shape (i.e., not necessary like a channel), therefore the results obtained from this study may not be directly applicable. Future studies are recommended to examine the effects of different settings on other types of shapes. Also, most cell phones nowadays are equipped with a very good camera. However, the cell phone camera typically has less control and is less precise than a typical consumer-grade camera. Future studies are recommended to test the limit of using a cell phone camera for a CRP survey.

\section{Conclusions}

Our study demonstrates that the accuracy of the measurement with the CGC-CRP method was strongly affected by camera shooting angle; image overlapping rate; as well as the shape, size, and orientation of the channels. As expected, the accuracy of the CGC-CRP method increased with image overlapping rate. To maintain an acceptable accuracy level, the image overlapping rate was suggested to be $\geq 70 \%$. On the other hand, contrary to the popular belief on higher accuracy with higher camera shooting angle, we found that the optimum shooting angle is in the range of $60^{\circ}$ to $80^{\circ}$ for measuring channels and the accuracy will drop either with higher or lower shooting angles. With respect to different channel shapes, the accuracy of V-channel was $\sim 15 \%$ higher than that of U-channel. With respect to channel orientation, for the U-channel, the impact of the orientation on the accuracy was not significant when the shooting angle was relatively high, whereas for the V-channel, the vertically oriented channel had higher accuracy than channels oriented horizontally or in an angle. Last, channel size did not strongly affect accuracy when the channel was vertically orientated when the shooting angle and image overlapping rate was set in the optimum range. However, when the shooting 
angle or image overlapping rate was low, or when the channel was angled or horizontally orientated, the accuracy was lower with larger channel size. The test on a soil surface in the field proved that the CGC-CRP method could provide centimeter-level accuracy for morphological measurements on channels and other field objects. Therefore, in soil erosion studies, the CGC-CRP method is probably accurate enough for measuring rill and gully erosion (which normally result in above centimeter-level elevation change or difference). The CGC-CRP method has a few advantages over the traditional method and the aerial photogrammetry method, which makes it uniquely suitable under various conditions for field survey of erosion channels.

Author Contributions: Conceptualization, F.Z., R.W., F.-R.M., D.L., and S.L.; methodology, F.Z., R.W., F.-R.M., and S.L.; software, F.Z. and R.W.; validation, F.Z. and S.L.; formal analysis, F.Z. and S.L.; investigation, F.Z.; resources, F.-R.M. and S.L.; data curation, F.Z. and S.L.; writing-original draft preparation, F.Z.; writing一review and editing, R.W., F.-R.M., D.L., and S.L.; visualization, F.Z.; supervision, S.L.; project administration, S.L.; funding acquisition, S.L. All authors have read and agreed to the published version of the manuscript.

Funding: Funds for this study were provided through Agriculture and Agri-Food Canada (AAFC) A-base projects "Sustainability measures to monitor and analyze the environmental impact of Canadian agriculture" and "Landscape Integrated Soil and Water Conservation (LISWC) on sloping fields under potato production in Atlantic Canada", as well as through a Canadian Natural Science and Engineering Research Council Discovery Grant.

Conflicts of Interest: The authors declare no conflicts of interest.

\section{References}

1. Lal, R. Soil degradation by erosion. Land Degrad. Dev. 2001, 12, 519-539. [CrossRef]

2. Pimental, D.; Sparks, D.L. Soil as an endangered ecosystem. Bioscience 2000, 50, 947. [CrossRef]

3. Pimentel, D. Soil erosion: A food and environmental threat. Environ. Dev. Sustain. 2006, 8, 119-137. [CrossRef]

4. Vereecken, H.; Schnepf, A.; Hopmans, J.W.; Javaux, M.; Or, D.; Roose, T.; Vanderborght, J.; Young, M.; Amelung, W.; Aitkenhead, M. Modeling soil processes: Review, key challenges, and new perspectives. Vadose Zone J. 2016, 15. [CrossRef]

5. Li, S.; Lobb, D.A.; Tiessen, K.H. Soil erosion and conservation based in part on the article "soil erosion and conservation" by w. S. Fyfe, which appeared in the encyclopedia of environmetrics. In Encyclopedia of Environmetrics; El-Shaarawi, A.H., Piegorsch, W.W., Chebana, F., Ouarda, T.B., Eds.; John Wiley \& Sons: Hoboken, NJ, USA, 2013; ISBN 0470973889.

6. Lal, R. Soil Erosion Research Methods, 2nd ed.; St. Lucie Press: Delray Beach, FL, USA, 1994; ISBN 1884015093.

7. Morgan, R.P.C. Soil Erosion and Conservation, 3rd ed.; Blackwell Pub.: Malden, MA, USA, 2005; ISBN 1405117818.

8. Hill, W.W.; Kaiser, V.G. Method of Measuring Soil Erosion Losses; Rill and Sheet Erosion; Soil Conservation Service: Washington, DC, USA, 1965; pp. 13-14.

9. Hudson, N. Field measurements of accelerated soil erosion in localized areas. Rhod. Agric. J. 1964, 31, 46-48.

10. Casalí, J.; Loizu, J.; Campo, M.; De Santisteban, L.; Álvarez-Mozos, J. Accuracy of methods for field assessment of rill and ephemeral gully erosion. CATENA 2006, 67, 128-138. [CrossRef]

11. McCool, D.; Dossett, M.; Yecha, S. Portable Rill Meter for Field Measurement of Soil Loss; Erosion and Sediment Transport Measurement: Symposium IAHS Publication: Florence, Italy, 1981; pp. 479-484.

12. Herweg, K. Field Manual for Assessment of Current Erosion Damage; University of Berne, Switzerland: Berne, Switzerland, 1996; ISBN 3906151077.

13. Goodwin, N.R.; Armston, J.D.; Muir, J.; Stiller, I. Monitoring gully change: A comparison of airborne and terrestrial laser scanning using a case study from aratula, queensland. Geomo 2017, 282, 195-208. [CrossRef]

14. Liu, H.; Qian, F.; Ding, W.; Gómez, J.A. Using 3d scanner to study gully evolution and its hydrological analysis in the deep weathering of southern china. CATENA 2019, 183, 104218. [CrossRef]

15. Wang, Q.; Liu, J.; Wu, L.; Xu, Z.; Fan, S.; Qian, A. Analysis of Gully Erosion Hazard Using High Resolution Terrestrial Lidar. In Proceedings of the 2016 IEEE International Geoscience and Remote Sensing Symposium (IGARSS), Beijing, China, 10-15 July 2016; pp. 7469-7472.

16. Yermolaev, O.; Gafurov, A.; Usmanov, B. Evaluation of erosion intensity and dynamics using terrestrial laser scanning. Eurasian Soil Sci. 2018, 51, 814-826. [CrossRef] 
17. Obu, J.; Lantuit, H.; Grosse, G.; Günther, F.; Sachs, T.; Helm, V.; Fritz, M. Coastal erosion and mass wasting along the canadian beaufort sea based on annual airborne Lidar elevation data. Geomo 2017, 293, 331-346. [CrossRef]

18. Ciprian Margarint, M.; Niculita, M.; Tarolli, P. Using UAV and Lidar Data for Gullies Erosion Monitoring; EGU General Assembly: Vienna, Austria, 2019; p. 8461.

19. Lindsay, J.B.; Francioni, A.; Cockburn, J.M. Lidar DEM smoothing and the preservation of drainage features. Remote Sens. 2019, 11, 1926. [CrossRef]

20. Fink, C.M.; Drohan, P.J. High resolution hydric soil mapping using Lidar digital terrain modeling. Soil Sci. Soc. Am. J. 2016, 80, 355-363. [CrossRef]

21. Maune, D.F. Digital Elevation Model Technologies and Applications: The DEM Users Manual, 3rd ed.; Asprs Publications: Bethesda, MA, USA, 2017; ISBN 1570830827.

22. Matthews, N.A.; U.S. Department of the Interior, Bureau of Land Management. Aerial and Close-Range Photogrammetric Technology: Providing Resource Documentation, Interpretation, and Preservation; U.S. Department of the Interior, Bureau of Land Management, National Operations Center: Denver, CO, USA, 2008.

23. Ullman, S. The interpretation of structure from motion. Proc. R. Soc. B 1979, 203, 405-426. [CrossRef]

24. Lowe, D.G. Distinctive image features from scale-invariant keypoints. Int. J. Comput. Vis. 2004, 60, 91-110. [CrossRef]

25. Stafford, D.B.; Coastal Engineering Research Center. An Aerial Photographic Technique for Beach Erosion Surveys in North Carolina; U. S. Army Coastal Engineering Research Center: Washington, DC, USA, 1971; p. 115.

26. Stafford, D.B.; Langfelder, J. Air photo survey of coastal erosion. Photogramm. Eng. 1971, 37, 565-575.

27. Thomas, A.; Welch, R. Measurement of ephemeral gully erosion. Trans. ASAE 1988, 31, 1723-1728. [CrossRef]

28. Thomas, A.; Welch, R.; Jordan, T. Quantifying concentrated-flow erosion on cropland with aerial photogrammetry. J. Soil Water Conserv. 1986, 41, 249-252.

29. Welch, R.; Jordan, T.; Thomas, A. A photogrammetric technique for measuring soil erosion. J. Soil Water Conserv. 1984, 39, 191-194.

30. Carollo, F.G.; Di Stefano, C.; Ferro, V.; Pampalone, V. Measuring rill erosion at plot scale by a drone-based technology. Hydrol. Processes 2015, 29, 3802-3811. [CrossRef]

31. Di Stefano, C.; Ferro, V. Measurements of rill and gully erosion in sicily. Hydrol. Processes 2011, 25, $2221-2227$. [CrossRef]

32. D'Oleire-Oltmanns, S.; Marzolff, I.; Peter, K.; Ries, J. Unmanned Aerial Vehicle (UAV) for monitoring soil erosion in morocco. Remote Sens. 2012, 4, 3390-3416. [CrossRef]

33. Giménez, R.; Marzolff, I.; Campo, M.; Seeger, M.; Ries, J.; Casalí, J.; Alvarez-Mozos, J. Accuracy of high-resolution photogrammetric measurements of gullies with contrasting morphology. Br. Soc. Geomorphol 2009, 34, 1915-1926. [CrossRef]

34. Martínez-Casasnovas, J.; Antón-Fernández, C.; Ramos, M. Sediment production in large gullies of the mediterranean area (ne spain) from high-resolution digital elevation models and geographical information systems analysis. Br. Soc. Geomorphol. 2003, 28, 443-456. [CrossRef]

35. Marzolff, I.; Poesen, J. The potential of $3 \mathrm{~d}$ gully monitoring with gis using high-resolution aerial photography and a digital photogrammetry system. Geomo 2009, 111, 48-60. [CrossRef]

36. Marzolff, I.; Poesen, J.; Ries, J.B. Short to medium-term gully development: Human activity and gully erosion variability in selected spanish gully catchments. Landf. Anal. 2011, 17, 111-116.

37. Smith, M.W.; Vericat, D. From experimental plots to experimental landscapes: Topography, erosion and deposition in sub-humid badlands from structure-from-motion photogrammetry. Earth Surf. Process. Landf. 2015, 40, 1656-1671. [CrossRef]

38. Wells, R.R.; Momm, H.G.; Castillo, C. Quantifying uncertainty in high-resolution remotely sensed topographic surveys for ephemeral gully channel monitoring. Earth Surf. Dynam. 2017, 5, 347. [CrossRef]

39. Kropáček, J.; Schillaci, C.; Salvini, R.; Maerker, M. Assessment of gully erosion in the upper awash, central ethiopian highlands based on a comparison of archived aerial photographs and very high resolution satellite images. Geogr. Fis. Din. Quat. 2016, 39, 161-170. [CrossRef]

40. Balaguer-Puig, M.; Marqués-Mateu, Á.; Lerma, J.L.; Ibáñez-Asensio, S. Estimation of small-scale soil erosion in laboratory experiments with structure from motion photogrammetry. Geomo 2017, 295, 285-296. [CrossRef] 
41. Castillo, C.; Marín-Moreno, V.; Pérez, R.; Muñoz-Salinas, R.; Taguas, E. Accurate automated assessment of gully cross-section geometry using the photogrammetric interface freexsapp. Earth Surf. Process. Landf. 2018, 43, 1726-1736. [CrossRef]

42. Castillo, C.; Pérez, R.; James, M.R.; Quinton, J.; Taguas, E.V.; Gómez, J.A. Comparing the accuracy of several field methods for measuring gully erosion. Soil Sci. Soc. Am. J. 2012, 76, 1319-1332. [CrossRef]

43. Eltner, A.; Kaiser, A.; Abellan, A.; Schindewolf, M. Time lapse structure-from-motion photogrammetry for continuous geomorphic monitoring. Earth Surf. Process. Landf. 2017, 42, 2240-2253. [CrossRef]

44. Gessesse, G.D.; Fuchs, H.; Mansberger, R.; Klik, A.; Rieke-Zapp, D.H. Assessment of erosion, deposition and rill development on irregular soil surfaces using close range digital photogrammetry. Photogramm. Rec. 2010, 25, 299-318. [CrossRef]

45. Kaiser, A.; Neugirg, F.; Rock, G.; Müller, C.; Haas, F.; Ries, J.; Schmidt, J. Small-scale surface reconstruction and volume calculation of soil erosion in complex moroccan gully morphology using structure from motion. Remote Sens. 2014, 6, 7050-7080. [CrossRef]

46. Prosdocimi, M.; Burguet, M.; Di Prima, S.; Sofia, G.; Terol, E.; Comino, J.R.; Cerdà, A.; Tarolli, P. Rainfall simulation and structure-from-motion photogrammetry for the analysis of soil water erosion in mediterranean vineyards. Sci. Total Environ. 2017, 574, 204-215. [CrossRef] [PubMed]

47. Wells, R.R.; Momm, H.G.; Bennett, S.J.; Gesch, K.R.; Dabney, S.M.; Cruse, R.; Wilson, G.V. A measurement method for rill and ephemeral gully erosion assessments. Soil Sci. Soc. Am. J. 2016, 80, 203-214. [CrossRef]

48. Rieke-Zapp, D.H.; Nearing, M.A. Digital close range photogrammetry for measurement of soil erosion. Photogramm. Rec. 2005, 20, 69-87. [CrossRef]

49. Butler, J.B.; Lane, S.N.; Chandler, J.H. Assessment of DEM quality for characterizing surface roughness using close range digital photogrammetry. Photogramm. Rec. 1998, 16, 271-291. [CrossRef]

50. Dai, F.; Feng, Y.; Hough, R. Photogrammetric error sources and impacts on modeling and surveying in construction engineering applications. Vis. Eng. 2014, 2, 2. [CrossRef]

51. Golparvar-Fard, M.; Bohn, J.; Teizer, J.; Savarese, S.; Peña-Mora, F. Evaluation of image-based modeling and laser scanning accuracy for emerging automated performance monitoring techniques. Automat. Constr. 2011, 20, 1143-1155. [CrossRef]

52. Mellerowicz, K.T.; Rees, H.W.; Chow, T.L.; Ghanem, I. Soils of the Black Brook Watershed St. Andre Parish, Madawaska County, New Brunswick; New Brunswick Dept. of Agriculture and Agriculture Canada: Fredericton, NB, Canada, 1993; p. 42.

53. Dall'Asta, E.; Thoeni, K.; Santise, M.; Forlani, G.; Giacomini, A.; Roncella, R. Network design and quality checks in automatic orientation of close-range photogrammetric blocks. Sensors 2015, 15, 7985-8008. [CrossRef] [PubMed]

54. Klaus, D.T. Surface Triangulation by Linear Interpolation in Intersecting Planes; Proc.SPIE: Paris, France, 1989.

55. DeRose, R.; Gomez, B.; Marden, M.; Trustrum, N. Gully erosion in Mangatu Forest, New Zealand, estimated from digital elevation models. Earth Surf. Process. Landf. 1998, 23, 1045-1053. [CrossRef]

56. Glendell, M.; McShane, G.; Farrow, L.; James, M.R.; Quinton, J.; Anderson, K.; Evans, M.; Benaud, P.; Rawlins, B.; Morgan, D. Testing the utility of structure-from-motion photogrammetry reconstructions using small Unmanned Aerial Vehicles and ground photography to estimate the extent of upland soil erosion. Earth Surf. Process. Landf. 2017, 42, 1860-1871. [CrossRef]

57. James, L.A.; Watson, D.G.; Hansen, W.F. Using Lidar data to map gullies and headwater streams under forest canopy: South carolina, USA. CATENA 2007, 71, 132-144. [CrossRef]

58. Robichaud, P.R.; Wagenbrenner, J.W.; Brown, R.E. Rill erosion in natural and disturbed forests: 1. Measurements. Water Resour. Res. 2010, 46. [CrossRef]

(C) 2020 by the authors. Licensee MDPI, Basel, Switzerland. This article is an open access article distributed under the terms and conditions of the Creative Commons Attribution (CC BY) license (http://creativecommons.org/licenses/by/4.0/). 